\title{
Substituição da brita pelo resíduo cerâmico do processo de fundição de precisão em concretos de alta resistência
}

\author{
Hueslei Grison Soares ${ }^{1}$ \\ Cleber Rodrigo de Lima Lessa ${ }^{1 *}$ (1)
}

\section{Resumo}

A presente pesquisa teve como objetivo estudar a viabilidade técnica da substituição da brita, em concretos de alta resistência de $500 \mathrm{kgf} / \mathrm{cm}^{2}(50 \mathrm{MPa})$, pelo resíduo proveniente dos moldes cerâmicos, produzidos pela fundição de precisão. Este resíduo acarreta danos financeiros e ambientais devido à grande dificuldade de ser reincorporado ao processo produtivo e, portanto, acaba obrigatoriamente sendo depositado em aterros industriais. Partindo das normas técnicas, o resíduo foi cominuído, caracterizado e incorporado a corpos de prova com variações de $25 \%, 50 \%, 75 \%$ e $100 \%$ em substituição da brita, para realização de ensaios de resistência à compressão, índices de consistência, absorção de água por capilaridade e por imersão. Quando comparados com padrão sem adição de resíduo, os resultados dos ensaios mostraram que este resíduo dos moldes cerâmicos pode ser usado como substituto do agregado graúdo em concretos. Portanto, o presente trabalho mostra ser possível uma reutilização do resíduo de fundição de precisão na indústria de construção civil.

Palavras-chave: Resíduos de moldes cerâmicos; Fundição de precisão; Concreto de alta resistência; Reutilização de resíduo.

\section{Replacement of the gravel by ceramic waste from the lost wax casting process in the high resistence concretes}

\begin{abstract}
This research aimed at the technical feasibility of gravel replacement by the residue from lost wax casting process in high resistance concrete of $500 \mathrm{kgf} / \mathrm{cm}^{2}(50 \mathrm{MPa})$. This residue entails financial and environmental losses due to the difficulty of being reused in the production process and, therefore, consequently destined for industrial landfills. According to standards, the residue was tested and characterized to be mixed in samples with variations of $25 \%, 50 \%, 75 \%$ e $100 \%$ in gravel replacement. After that, compressive strength, consistency index, absorption of water by capillarity and immersion tests were performed. When compared to the standard without residue addition, the results showed that the residue can be used as gravel replacement in high strength concrete. Therefore, the present work shows that it is possible to reuse the residue from lost wax casting process in the construction industry.
\end{abstract}

Keywords: Residue from casting; Lost wax casting; High resistance concrete; Reuse of residue.

\section{Introdução}

Atualmente, a indústria brasileira, tem cerca de 33 fundições que trabalham com o processo de fundição de precisão, sendo a maioria de pequeno e médio porte, estando concentradas nas regiões Sul e Sudeste do país. Nesse processo é gerado um resíduo cerâmico denominado casca refratária ou casca cerâmica, que é inviável de ser reutilizada no processo produtivo, devido à grande quantidade de materiais que a compõem e a dificuldade de sua separação. Portanto, o resíduo da casca normalmente é depositado em aterros industriais o que acarreta em altos custos e um grande prejuízo ambiental $[1,2]$.

Conforme o Instituto Brasileiro de Geografia e Estatística [3], foi apontado no ano de 2008 que apenas 22,54\% dos municípios brasileiros possuem aterros controlados e possuem $27,68 \%$ aterros sanitários, onde só $11,56 \%$ têm unidade de triagem de resíduos recicláveis. Esta prática de descarte inadequado provoca consequências danosas à saúde pública e ao meio ambiente.

IPrograma de Pós-Graduação em Tecnologia e Engenharia dos Materiais do Instituto Federal do Rio Grande do Sul - PPGTEM - IFRS, campus Caxias do Sul, RS, Brasil.

*Autor correspondente: cleber.lessa@caxias.ifrs.edu.br 
O concreto demanda uma grande quantidade de materiais inertes, como a areia e a brita. A extração de material inerte de formações rochosas em áreas acidentadas e montanhosas também é uma atividade que causa danos ao meio ambiente, uma vez que altera a paisagem e provoca problemas de estabilidade [4].

O foco do presente estudo é demonstrar a reutilização dos resíduos cerâmicos da fundição de precisão para a substituição total ou parcial do agregado graúdo presente no concreto, que traz por consequências, benefícios ambientais com a diminuição da retirada de recursos naturais, e diminuição da utilização de aterros industriais. Por fim, possibilita uma redução de custos para a construção civil e para o setor de fundição de precisão pelo fato de trazer uma possível solução para descarte.

\section{Materiais e métodos}

Como materiais para a execução dos concretos foram usados, água potável de empresa de distribuição local, Superplastificante do tipo I, com base química de naftaleno-sulfonato, fornecido por empresa do ramo de

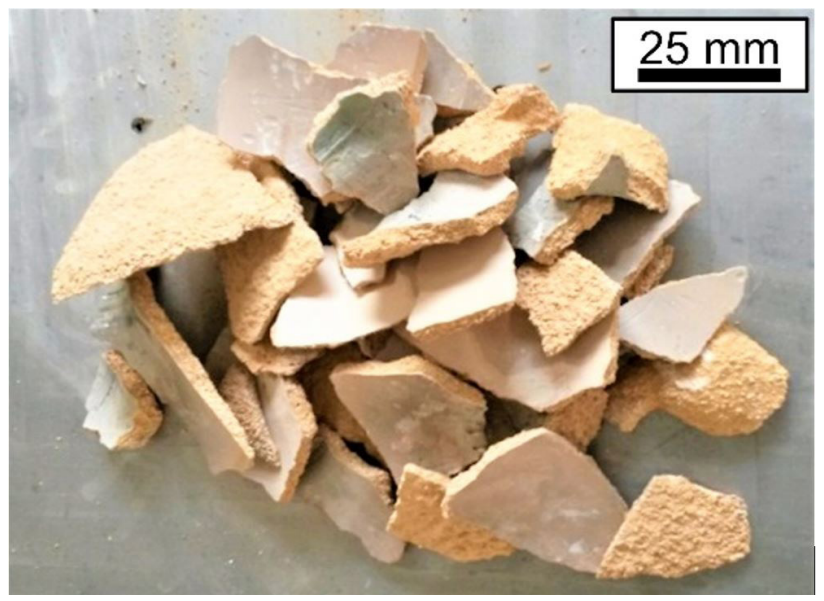

Figura 1. Resíduo de casca cerâmica em forma de lascas proveniente do processo de Fundição de precisão. aditivos para concreto, Cimento Portland (CP V - ARI) de alta resistência inicial e sem adições, agregado miúdo (areia média) de origem quartzosa, agregado graúdo (brita - basalto do tipo A) de rochas basálticas e fratura lamelar da região serrana do Rio Grande do Sul (RS) e a casca cerâmica em forma de lascas (Figura 1), coletada em empresa atuante na área de fundição de precisão, no município de Caxias do $\mathrm{Sul} / \mathrm{RS}$, com um parque fabril de $35.000 \mathrm{~m}^{2}$ e capacidade de produção de 120 t/mês de peças.

O resíduo da casca cerâmica foi cominuído manualmente por golpes com auxílio de uma haste metálica e peneirado chegando a faixas granulométricas semelhantes às encontradas no agregado graúdo (Figura 2), ambos dentro dos padrões mencionados pela norma ABNT NBR 7211:2015 [5], evidenciados na Tabela 1 e Tabela 2.

Para as propriedades físicas da massa unitária e do volume de vazios dos agregados, foi utilizada norma ABNT NBR NM 45:2006 [6] e para a massa específica, massa específica aparente e absorção de água a ABNT NBR NM 53:2009 [7].

Para obtenção da composição química foi utilizada a análise de Fluorescência por raio X (FRX) a partir do equipamento da marca Shimadzu, modelo XRF - 1800, com fonte de radiação de $\mathrm{Rh}$, potência de $4 \mathrm{~kW}$, operado em 40 $\mathrm{kV}$ e $80 \mathrm{~mA}$. A cristalinidade do resíduo foi determinada no difratômetro de raios $\mathrm{X}$ da marca Philips, modelo XPert com fonte de radiação $\mathrm{Cu}-\mathrm{K} \alpha$, e as fases cristalinas foram identificadas com o auxílio do software XPert HighScore, através de comparação do difratograma da amostra. Ambos os ensaios foram realizados no Laboratório de Materiais Cerâmicos (LACER - UFRGS).

Com o intuito de obter um concreto de alta resistência de $500 \mathrm{kgf} / \mathrm{cm}^{2}$ (50 MPa), foi usado o método de dosagem CIENTEC [8], chegando a um traço de 1 parte de cimento para 1,56 partes de areia, 1,71 partes de brita e uma relação água/cimento de 0,45. Em função da adição de resíduo reduzir a plasticidade do concreto, foi adicionado, com referência à massa de resíduo, $0,61 \%$ de plastificante e $1,2 \%$ de água, em massa, para cada formulação.
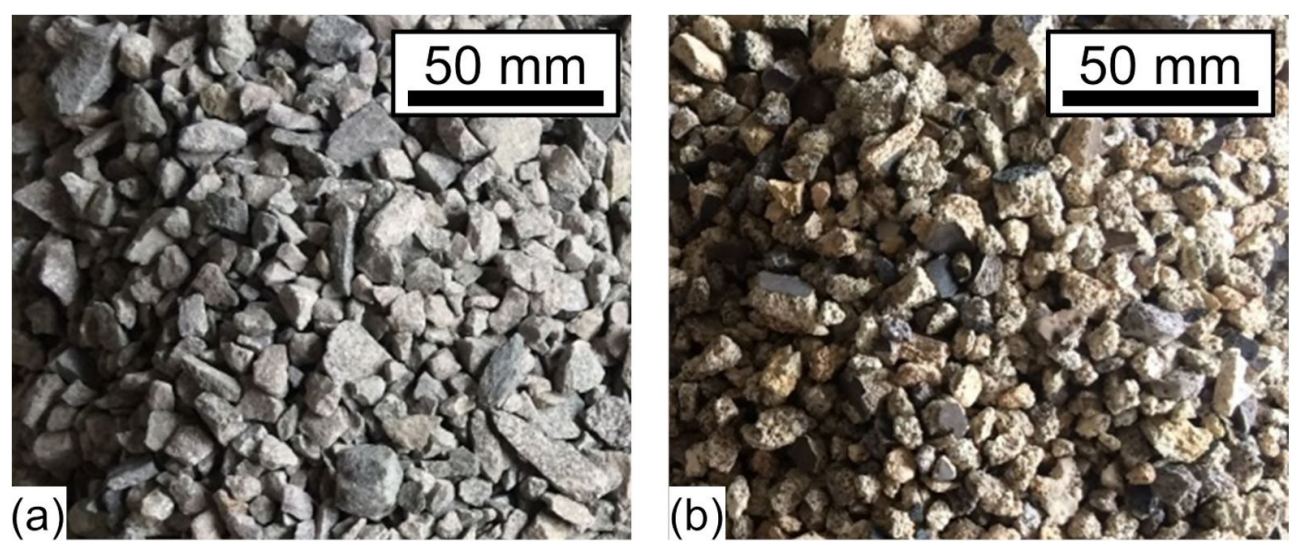

Figura 2. Materiais para a execução dos concretos. (a) Agregado graúdo natural (brita); (b) Resíduo da casca cerâmica após peneirado em faixas granulométricas semelhante ao agregado natural. 
Tabela 1. Resultado do ensaio granulométrico do agregado graúdo natural (brita)

\begin{tabular}{|c|c|c|c|c|}
\hline \multicolumn{5}{|c|}{ Agregado graúdo natural (Brita) } \\
\hline \multirow{3}{*}{$\begin{array}{c}\begin{array}{c}\text { Abertura das peneiras } \\
(\mathrm{mm})\end{array} \\
\text { (ABNT NBR NM }\end{array}$} & \multicolumn{4}{|c|}{ Percentual de massa retida } \\
\hline & \multirow{2}{*}{\multicolumn{2}{|c|}{$\begin{array}{c}\text { (ABNT NBR 7211:2005) } \\
\text { Zona Utilizável Acumulada } \\
\end{array}$}} & \multicolumn{2}{|c|}{ Amostra } \\
\hline & & & Média Retida & Média Retida \\
\hline ISO 3310-1) & Inferior & Superior & Acumulada (\%) & $(\%)$ \\
\hline 12,5 & 0 & 5 & 1 & 1 \\
\hline 9,5 & 2 & $15^{2}$ & 16 & 16 \\
\hline 6,3 & $40^{2}$ & $65^{2}$ & 59 & 44 \\
\hline 4,75 & $80^{2}$ & 100 & 85 & 26 \\
\hline 2,36 & 92 & 100 & 99 & 14 \\
\hline 0 & 95 & 100 & 100 & 1 \\
\hline
\end{tabular}

Módulo de finura encontrado: 6,56

Nota: ${ }^{2}$ Em cada zona granulométrica deve ser aceita uma variação de no máximo cinco unidades percentuais em apenas um dos limites marcados. Esta variação também pode estar distribuída em vários desses limites.

Tabela 2. Resultados do ensaio granulométrico do resíduo após cominuído e peneirado

\begin{tabular}{|c|c|c|c|c|}
\hline \multicolumn{5}{|c|}{ Resíduo cerâmico após processamento } \\
\hline \multirow{2}{*}{$\begin{array}{c}\text { Abertura das peneiras } \\
(\mathbf{m m})\end{array}$} & \multicolumn{4}{|c|}{$\begin{array}{ll}\text { Percentual de massa retida } \\
\end{array}$} \\
\hline & \multirow{2}{*}{\multicolumn{2}{|c|}{$\begin{array}{c}\text { (ABNT NBR 7211:2005) } \\
\text { Zona Utilizável Acumulada }\end{array}$}} & \multicolumn{2}{|c|}{ Amostra } \\
\hline (ABNT NBR NM & & & Média Retida & Média Retida \\
\hline ISO 3310-1) & Inferior & Superior & Acumulada (\%) & $(\%)$ \\
\hline 12,5 & 0 & 5 & 1 & 1 \\
\hline 9,5 & 2 & $15^{2}$ & 17 & 16 \\
\hline 6,3 & $40^{2}$ & $65^{2}$ & 52 & 35 \\
\hline 4,75 & $80^{2}$ & 100 & 78 & 27 \\
\hline 2,36 & 95 & 100 & 99 & 21 \\
\hline Fundo & 100 & 100 & 100 & 0 \\
\hline
\end{tabular}

Módulo de finura encontrado: 6,44

Nota: ${ }^{2}$ Em cada zona granulométrica deve ser aceita uma variação de no máximo cinco unidades percentuais em apenas um dos limites marcados. Esta variação também pode estar distribuída em vários desses limites.

Seguindo os procedimentos descritos pela norma ABNT NBR 5738:2015 [9], foram executadas cinco formulações de concreto, isoladas, e misturadas em betoneira de 120 litros, o de referência (sem adição de resíduo), com $25 \%$, $50 \%, 75 \%$ e $100 \%$ de resíduo em substituição do agregado graúdo. Para cada formulação foram montados cinco corpos de prova com $100 \mathrm{~mm}$ de diâmetro por $200 \mathrm{~mm}$ de altura para execução do ensaio de resistência à compressão, mais cinco corpos de prova no diâmetro de $50 \mathrm{~mm}$ por $100 \mathrm{~mm}$ de altura para os demais ensaios.

Após a execução completa do concreto foi seguida a Norma ABNT NBR NM 67:1998 [10], para determinar o grau de escoamento do concreto pelo abatimento do tronco cone, usando como referência um abatimento de $110 \pm 30 \mathrm{~mm}$.

$\mathrm{O}$ ensaio de resistência à compressão foi realizado depois de transcorridos 3, 7 e 28 dias de cura em prensa hidráulica de empresa do ramo de concreto de Caxias do Sul, seguindo a norma ABNT NBR 5739:2015 [11]. Este ensaio foi replicado e passou por um tratamento estatístico com o intuito de comparar o padrão sem adição de resíduo com os concretos contendo resíduo [12].

$\mathrm{O}$ ensaio de absorção de água por capilaridade foi realizado seguindo a norma ABNT NBR 9779:2015 [13]. Ensaio de absoção de água por imersão foi realizado seguindo a norma ABNT NBR 9778:1986 [14].

\section{Resultados e discussão}

No gráfico de faixas granulométricas da Figura 3 é possível observar que ambos os agregados (brita e resíduo) se mantiveram dentro das zonas utilizáveis inferior e superior, com pequenas variações, mas dentro da tolerância aceitável segundo a norma ABNT NBR 7211:2015 [5], consequentemente apresentaram um módulo de finura muito próximo um do outro (brita $=6,56$ e resíduo $=6,44$ ) reforçando a ideia da semelhança entre os agregados.

As curvas ainda evidenciam que os materiais apresentam granulometria contínua, que é desejável para a produção de concretos, pois permite um melhor arranjo entre as partículas do agregado, aumentando o efeito de empacotamento entre os grãos [15].

Analisando as propriedades físicas dos agregados é possível notar uma menor massa unitária, massa específica, massa específica aparente e massa específica saturada superfície seca, isso se dá em função da maior porosidade do resíduo cerâmico (Tabela 3). Esta porosidade consequentemente aumenta o índice de volume de vazios influenciando em uma maior absorção de água. Já as dimensões máximas de ambos os agregados se mantiveram iguais em virtude do controle de peneiramento do resíduo durante o seu processamento. 


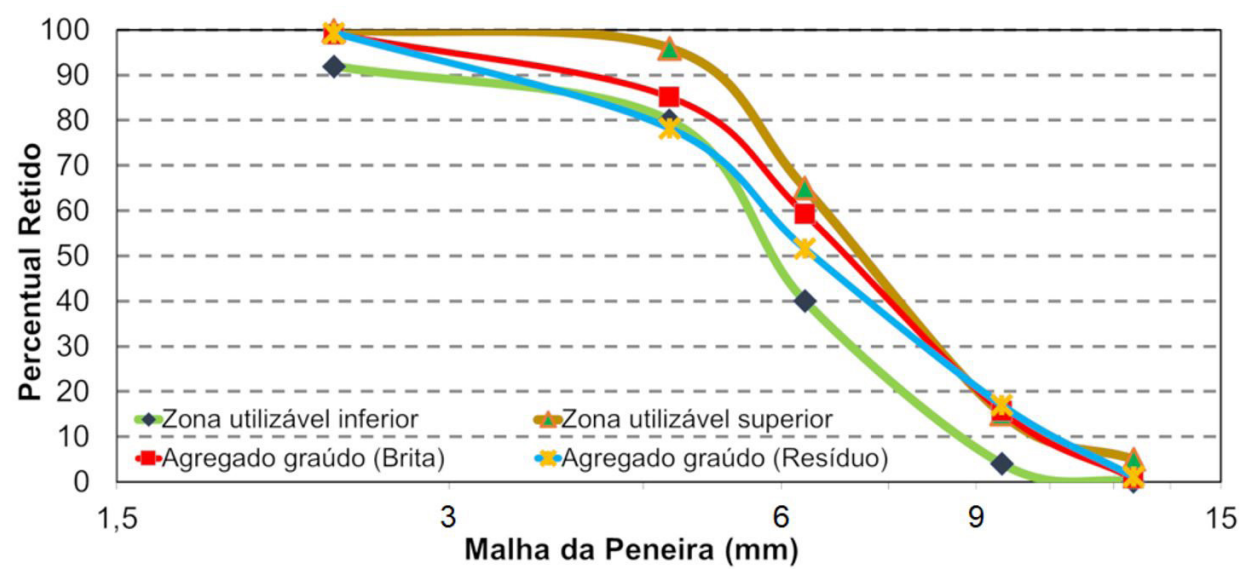

Figura 3. Faixas granulométricas obtidas, para o agregado graúdo natural (brita) e o resíduo da casca cerâmica cominuído.

Tabela 3. Comparação de algumas propriedades físicas encontradas para os agregados usados na pesquisa.

\begin{tabular}{cccc}
\hline & \multicolumn{2}{c}{ Agregado Graúdo } & Agregado Miúdo \\
\cline { 2 - 4 } & Brita & Resíduo & Areia \\
\hline Massa unitária & $1303,41 \mathrm{~kg} / \mathrm{m}^{3}$ & $1012,53 \mathrm{~kg} / \mathrm{m}^{3}$ & $1739,01 \mathrm{~kg} / \mathrm{m}^{3}$ \\
Dimensão Máxima & $12,5 \mathrm{~mm}$ & $12,5 \mathrm{~mm}$ & - \\
Índice de volume de vazios & $47,74 \%$ & $49,25 \%$ & $28,66 \%$ \\
Absorção de água & $2,10 \%$ & $9,30 \%$ & - \\
Massa esp. aparente seca & $2,60 \mathrm{~g} / \mathrm{cm}^{3}$ & $2,00 \mathrm{~g} / \mathrm{cm}^{3}$ & $2,44 \mathrm{~g} / \mathrm{cm}^{3}$ \\
Massa esp. saturada sup. seca & $2,65 \mathrm{~g} / \mathrm{cm}^{3}$ & $2,20 \mathrm{~g} / \mathrm{cm}^{3}$ & $2,53 \mathrm{~g} / \mathrm{cm}^{3}$ \\
Massa especifica & $2,84 \mathrm{~g} / \mathrm{cm}^{3}$ & $2,47 \mathrm{~g} / \mathrm{cm}^{3}$ & $2,69 \mathrm{~g} / \mathrm{cm}^{3}$ \\
Dimensão & $\mathrm{ND}$ & $\mathrm{ND}$ & $\mathrm{ND}$ \\
\hline
\end{tabular}

$\mathrm{ND}=$ Não determinada.

Tabela 4. Resultado da Fluorescência de raios X (FRX) do resíduo cerâmico do processo de fundição de precisão.

\begin{tabular}{cc}
\hline Composto Químico & Teor Encontrado \\
\hline $\mathrm{SiO}_{2}$ & $56,72 \%$ \\
$\mathrm{Al}_{2} \mathrm{O}_{3}$ & $34,17 \%$ \\
$\mathrm{Fe}_{2} \mathrm{O}_{3}$ & $3,5 \%$ \\
$\mathrm{TiO}_{2}$ & $2,22 \%$ \\
$\mathrm{ZrO}_{2}$ & $1,49 \%$ \\
$\mathrm{~K}_{2} \mathrm{O}$ & $1,12 \%$ \\
$\mathrm{CaO}$ & $0,27 \%$ \\
$\mathrm{P}_{2} \mathrm{O}_{5}$ & $0,16 \%$ \\
$\mathrm{Cr}_{2} \mathrm{O}_{3}$ & $0,07 \%$ \\
$\mathrm{NbO}$ & $0,07 \%$ \\
$\mathrm{Outros}$ & $0,2 \%$ \\
\hline
\end{tabular}

Nos resultados da fluorescência por raios $\mathrm{X}$ apresentados na Tabela 4, ficou evidente como sendo os principais compostos do resíduo, $\mathrm{SiO}_{2}, \mathrm{Al}_{2} \mathrm{O}_{3}, \mathrm{Fe}_{2} \mathrm{O}_{3}$ e TiO , correspondendo a $96,6 \%$ da composição, confirmando os mesmos componentes utilizados para a fabricação da casca cerâmica do molde que são a sílica coloidal $-\mathrm{SiO}_{2}$ (aglomerante), mulita $-3 \mathrm{Al}_{2} \mathrm{O}_{3} .2 \mathrm{SiO}_{2}$, areia de zircônio - $\mathrm{Zr}$ (refratários) e frações de Fe e Ti provenientes do metal vazado.

No difratograma de raios X apresentado na Figura 4 podem ser observados picos bem definidos, que correspondem às fases cristalinas cristobalita $\left(\mathrm{SiO}_{2}\right)$, mulita $\left(3 \mathrm{Al}_{2} \mathrm{O}_{3}-2 \mathrm{SiO}_{2}\right)$ e rutilo $\left(\mathrm{TiO}_{2}\right)$, corroborando com o resultado de análise química por FRX.

Com 3 dias de cura os concretos com $25 \%$ e $50 \%$ de resíduo cerâmico em substituição da brita ultrapassaram $20 \mathrm{MPa}$ de resistência à compressão sendo estatisticamente, segundo o método de análise de Tukey [12], considerados iguais ao concreto referência sem adição de resíduo, com um percentual de confiança de $95 \%$. Nos concretos com $75 \%$ e $100 \%$ de resíduo, segundo o método de Tukey [12], não foram considerados iguais à referência, apresentando respectivamente uma queda de $10 \%$ e $16 \%$ na resistência à compressão.

Decorridos 7 dias de cura os concretos com $50 \%$ e $100 \%$ de substituição da brita pelo resíduo cerâmico sofreram uma pequena queda na resistência a compressão, sendo $5 \%$ e $8 \%$ respectivamente, que segundo o método de análise de Tukey [12] pode ser considerada igual ao concreto referência sem adição de resíduo, com um percentual de confiança de $95 \%$.

Ambos os concretos, com substituição do agregado graúdo (brita) pelo resíduo, após os 28 dias de cura atingiram a resistência mecânica no ensaio de compressão acima de 500 $\mathrm{kgf} / \mathrm{cm}^{2}$ (50 MPa), conforme Figura 5, sendo considerados concretos de alta resistência, com exceção do concreto com substituição total da brita pelo resíduo, ficando apenas 3\% abaixo do desejado. Estatisticamente segundo o método 


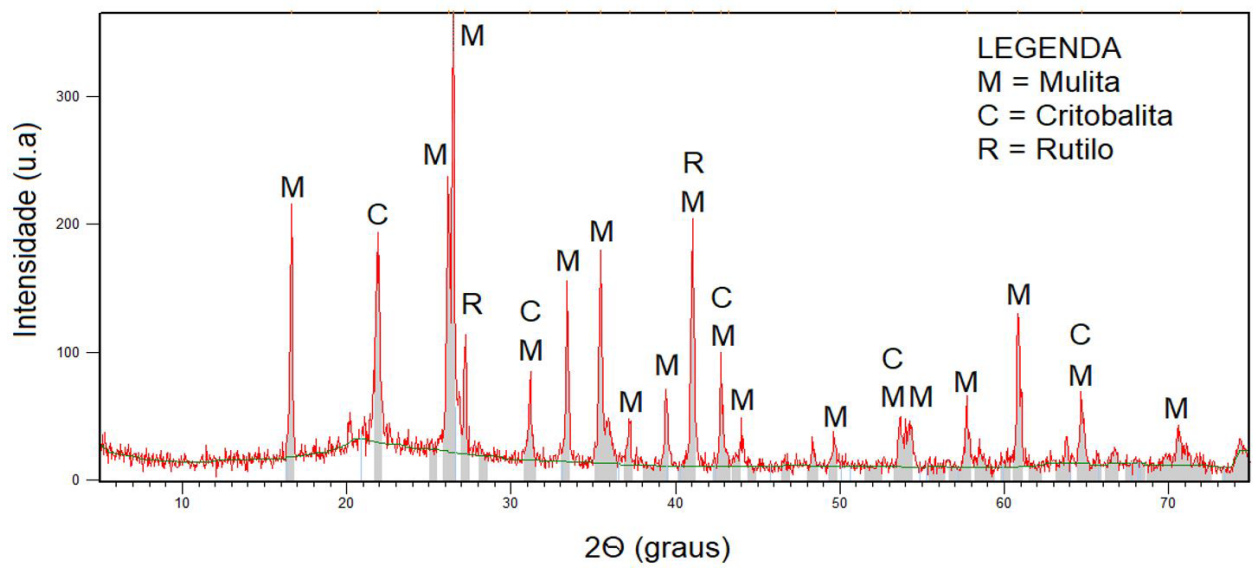

Figura 4. Difratograma de raios $X$ da casca cerâmica do processo de fundição de precisão.

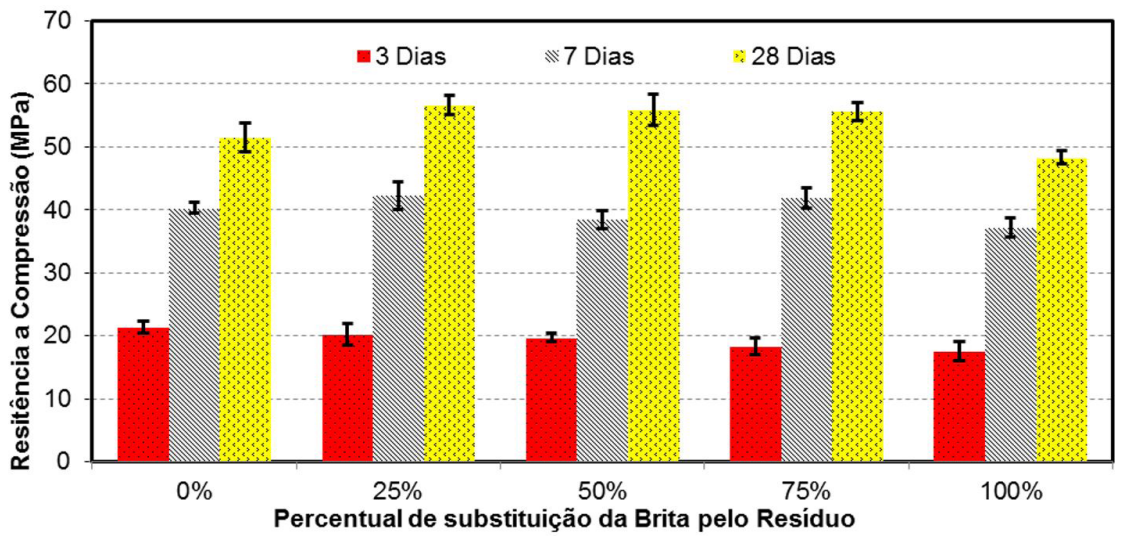

Figura 5. Resultados dos ensaios de resistência à compressão após 3, 7 e 28 dias de cura.

de análise de Tukey [12] todas as formulações podem ser consideradas iguais ao concreto de referência sem adição de resíduo, com um percentual de confiança de 95\%.

A substituição da brita pelo resíduo até o percentual de $75 \%$ acarretou em um aumento significativo na resistência à compressão dos corpos de prova após 28 dias de cura quando comparados ao padrão sem a adição de resíduo, chegando a um incremento de até $10 \%$, seguindo um padrão muito semelhante às pesquisas de Rashid et al. [16], que estudaram um concreto sustentável com a substituição parcial dos agregados por resíduos cerâmicos, evidenciando um aumento na resistência à compressão quando substituiu até $30 \%$ do agregado.

O concreto com substituição total da brita pelo resíduo, decorridos 28 dias de cura, mostrou uma queda de $6 \%$ na resistência à compressão, isso se dá principalmente devido à adição de água para melhorar o escoamento conforme evidenciado em estudos realizados por Anderson et al. [17], que afirmam que a adição de água reduz a resistência mecânica dos concretos em função de um aumento na porosidade após sua completa secagem; ainda assim reforçam que o uso do residuo cerâmico como um substituto para o agregado graúdo em concretos é certamente viável.

Com relação ao grau de escoamento fica evidente que conforme se adiciona resíduo o escoamento é comprometido, chegando a uma redução de até $92 \%$ quando é substituída a brita em sua totalidade, seguindo o mesmo padrão encontrado nos estudos de Anderson et al. [17], que trocaram a brita por resíduo cerâmico.

Com a adição de $0,61 \%$ de plastificante e $1,2 \%$ de água, em massa, em função da quantidade de resíduo, foi possível atingir o grau de escoamento dentro das tolerâncias desejadas entre $110 \pm 30 \mathrm{~mm}$ (Figura 6).

É notório que a quantidade de resíduo adicionado eleva a absorção de água por capilaridade (Figura 7), isso é justificado em função da porosidade no resíduo cerâmico, vindo de encontro aos estudos de Elçi [18], que utilizou resíduos de pisos porcelanato e revestimentos cerâmicos triturados como agregados na produção de concreto e observou um aumento na absorção de água.

Os resultados dos ensaios de absorção de água por imersão, apresentados na Figura 8, mostram mesmo comportamento padrão do ensaio de capilaridade, onde a adição de resíduo de casca provoca um aumento na absorção de água, também justificado pela porosidade do resíduo em questão; no entanto essa absorção se mostra proporcional à quantidade de resíduo em substituição da brita, diferindo do ensaio de capilaridade onde até $50 \%$ seguiu a mesma proporcionalidade posteriormente tendo um pico mais acentuado. 


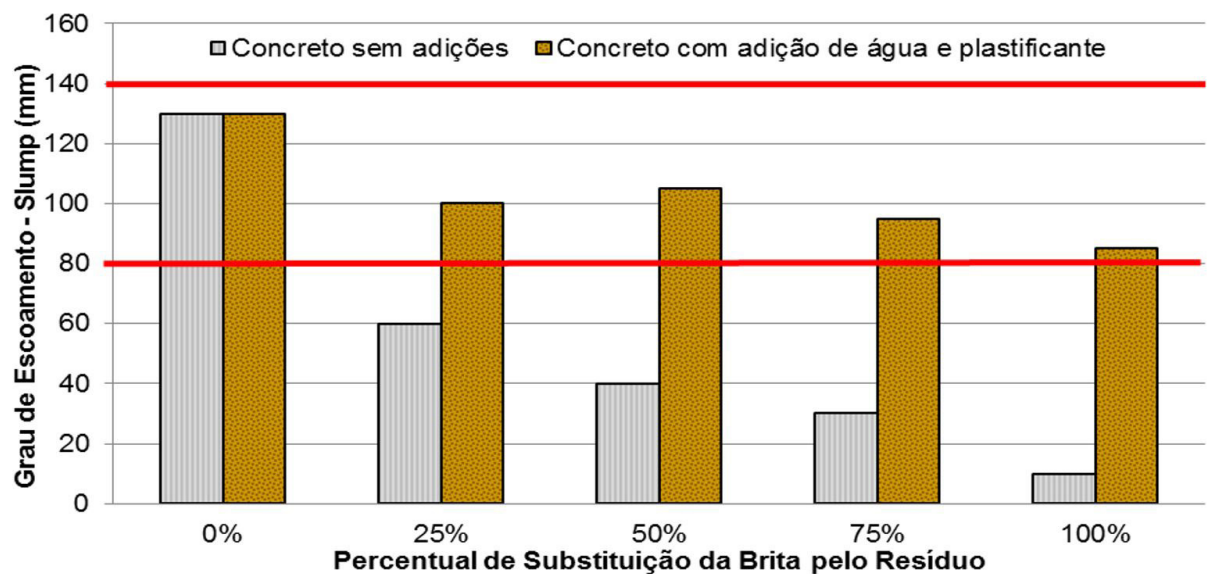

Figura 6. Grau de escoamento (slump test) do concreto no estado fresco com e sem adição de água e aditivo plastificante.

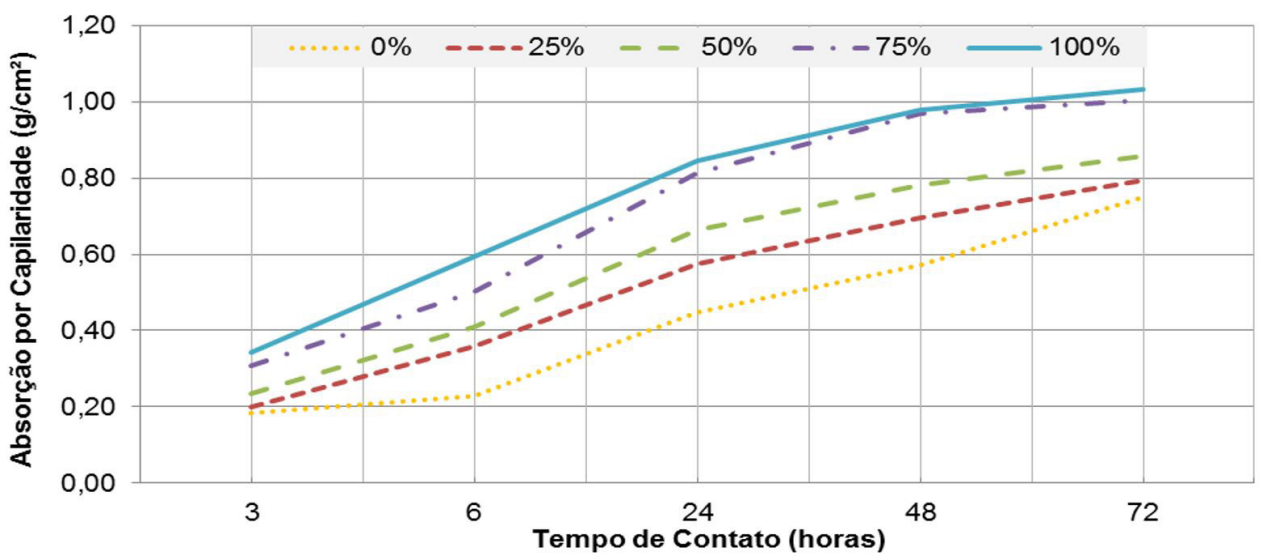

Figura 7. Resultado do ensaio de absorção de água por capilaridade após 28 dias de cura.

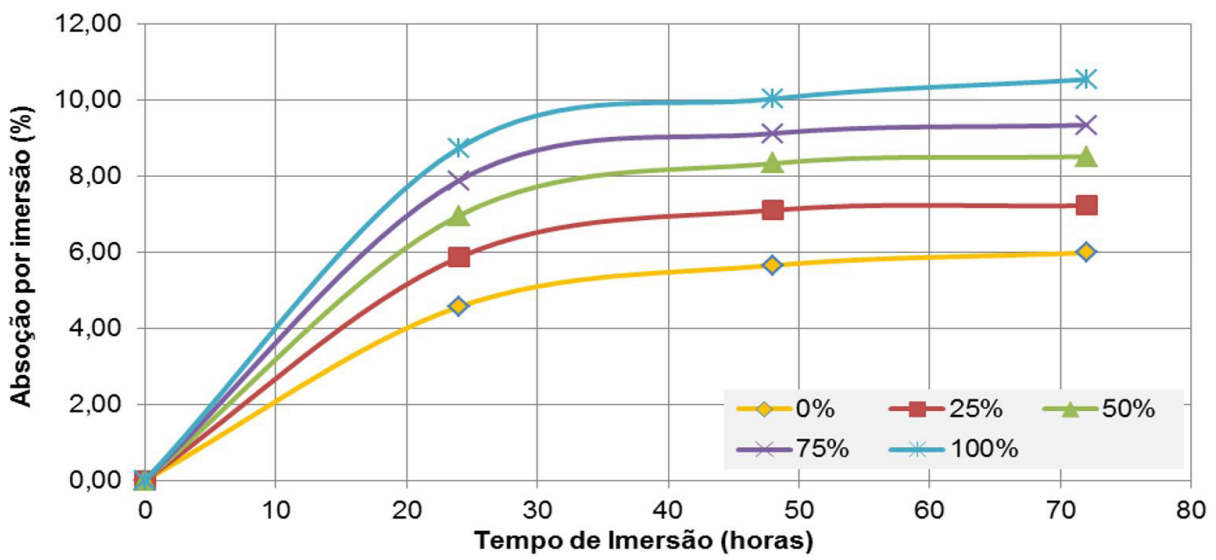

Figura 8. Resultado do ensaio de absorção de água por imersão após 28 dias de cura.

\section{Conclusão}

Após a verificação da utilização do resíduo cerâmico da fundição de precisão na substituição total ou parcial do agregado graúdo presente no concreto, foi possível destacar os seguintes pontos:

- Fica evidente a queda do grau de escoamento do concreto com substituição da brita pelo resíduo, chegando a uma redução de até $92 \%$ em sua totalidade, entretanto é possível chegar a um grau de escoamento muito semelhante com a adição de apenas $0,61 \%$ de aditivo superplastificantes e 1,25\% de água, em função da massa de resíduo adicionado;

- Com a substituição investigada colocada em pratica, é possível fazer uma economia considerável na questão do descarte em aterros; 
- Além da economia supracitada, também se destaca a diminuição na utilização de recursos naturais como o agregado graúdo (brita);

- O aproveitamento do resíduo cerâmico em concretos vai de encontro com as políticas atuais de produção mais verde;

- Independentemente da quantidade de resíduo substituída os concretos após 7 e 28 dias de cura poder ser considerados de mesma resistência à compressão do concreto padrão, apenas o concreto com $100 \%$ de resíduo aos 3 dias de cura não pode ser considerado de mesma resistência à compressão;

- Principalmente os resultados indicam que, a substituição em sua totalidade, do agregado graúdo que integra o concreto pelo resíduo cerâmico proveniente do processo de fundição de precisão, é possível sem causar prejuízos na resistência à compressão, que torna viável a sua aplicação.

\section{Referências}

1 Machado, C. F. Reutilização da casca cerâmica do processo de fundição por cera perdida como adição em matrizes cimentícias [dissertação]. Belo Horizonte: Centro Federal de Educação tecnológica de Minas Gerais; 2013.

2 Associação Brasileira de Fundição. Revista Fundição e Matérias Primas. 179. ed. São Paulo: ABIFA; 2015 [atualizada em 20 nov. 2018; acesso em 10 dez. 2018]. Disponível em: http://abifa.org.br/wp-content/ uploads/2015/05/revista-abifa-2015-04.pdf

3 Instituto Brasileiro de Geografia e Estatística. Pesquisa nacional de saneamento básico. Rio de Janeiro: IBGE; 2010. [atualizada em 12 jun. 2017; acesso em 19 abr. 2018]. Disponível em: https://biblioteca.ibge.gov.br/visualizacao/ livros/liv45351.pdf

4 Tedesco M. Estudo da utilização de resíduo de casca cerâmica da microfusão no concreto em substituição ao agregado graúdo e miúdo natural [dissertação]. Porto Alegre: Universidade Federal do Rio Grande do Sul; 2016.

5 Associação Brasileira de Normas Técnicas - ABNT. NBR 7211: agregados para concreto: especificação. Rio de Janeiro: ABNT; 2005.

6 Associação Brasileira de Normas Técnicas - ABNT. NBR NM 45: agregados: determinação de massa unitária e do volume de vazios. Rio de Janeiro: ABNT; 2006.

7 Associação Brasileira de Normas Técnicas - ABNT. NBR NM 53: agregado graúdo: determinação de massa especifica, massa especifica aparente e absorção de água. Rio de Janeiro: ABNT; 2009.

8 Recena FAP. Dosagem e controle da qualidade de concretos convencionais de cimento Portland. 3. ed. Porto Alegre: EDIUCRS; 2011.

9 Associação Brasileira de Normas Técnicas - ABNT. NBR 5738: procedimento para moldagem e cura de corpos-deprova. Rio de Janeiro: ABNT; 2015.

10 Associação Brasileira de Normas Técnicas - ABNT. NBR NM 67: concreto: determinação da consistência pelo abatimento do tronco cone. Rio de Janeiro: ABNT; 1998.

11 Associação Brasileira de Normas Técnicas - ABNT. NBR 5739: cimento Portland: ensaios de compressão de corpos-de-prova cilíndricos. Rio de Janeiro: ABNT; 2015.

12 Montgomery DC. Design and analysis of experiments. 5th ed. New York: John Wiley \& Sons; 2001.

13 Associação Brasileira de Normas Técnicas - ABNT. NBR 9779: argamassa e concreto endurecido: determinação da absorção da água por capilaridade: método de ensaio. Rio de Janeiro: ABNT; 2015.

14 Associação Brasileira de Normas Técnicas - ABNT. NBR 9778: argamassa e concreto endurecido: determinação da absorção da água por imersão: índice de vazios e massa especifica. Rio de Janeiro: ABNT; 1986.

15 Neville AM. Propriedades do concreto. 5. ed. Porto Alegre: Bookman; 2016.

16 Rashid K, Razzaq A, Ahmad M, Rashid T, Tariq S. Experimental and analytical selection of sustainable recycled concrete with ceramic waste aggregate. Construction \& Building Materials. 2017;154:829-840.

17 Anderson DJ, Smith ST, Au FTK. Mechanical properties of concrete utilising waste ceramic as coarse aggregate. Construction \& Building Materials. 2016;117:20-28.

18 Elçi H. Utilisation of crushed floor and wall tile wastes as aggregate in concrete production. Journal of Cleaner Production. 2016;112:742-752.

Recebido em: 24 Ago. 2019

Aceito em: 5 Abr. 2020 